\title{
Sulforaphane pretreatment prevents systemic inflammation and renal injury in response to cardiopulmonary bypass
}

\author{
Bao Nguyen, MRCS, ${ }^{a}$ Le Luong, PhD, ${ }^{b}$ Hatam Naase, MRCS, ${ }^{a}$ Marc Vives, PhD, ${ }^{c}$ Gentjan Jakaj, MRCS, ${ }^{a}$ \\ Jonathan Finch, MRCS, ${ }^{\mathrm{a}}$ Joseph Boyle, PhD, FRCPath, ${ }^{\mathrm{a}}$ John W. Mulholland, BSc, \\ Jong-hwan Kwak, PhD, ${ }^{\mathrm{e}}$ Suhkneung Pyo, PhD, ${ }^{\mathrm{e}}$ Amalia de Luca, MSc, ${ }^{\mathrm{a}}$ Thanos Athanasiou, PhD, FRCS, ${ }^{\mathrm{f}}$ \\ Gianni Angelini, FMedSci, FRCS, ${ }^{\mathrm{f}}$ Jon Anderson, FRCS, ${ }^{\mathrm{f}}$ Dorian O. Haskard, DM, FRCP, ${ }^{\mathrm{a}}$ and \\ Paul C. Evans, $\mathrm{PhD}^{\mathrm{b}}$
}

Objectives: Systemic inflammatory responses are a major cause of morbidity and mortality in patients undergoing cardiac surgery with cardiopulmonary bypass. However, the underlying molecular mechanisms for systemic inflammation in response to cardiopulmonary bypass are poorly understood.

Methods: A porcine model was established to study the signaling pathways that promote systemic inflammation in response to cardiac surgery with cardiopulmonary bypass under well-controlled experimental conditions. The influence of sulforaphane, an anti-inflammatory compound derived from green vegetables, on inflammation and injury in response to cardiopulmonary bypass was also studied. Intracellular staining and flow cytometry were performed to measure phosphorylation of p38 mitogen-activated protein kinase and the transcription factor nuclear factor- $\kappa \mathrm{B}$ in granulocytes and mononuclear cells.

Results: Surgery with cardiopulmonary bypass for 1 to 2 hours enhanced phosphorylation of p38 (2.5-fold) and nuclear factor- $\kappa \mathrm{B}$ (1.6-fold) in circulating mononuclear cells. Cardiopulmonary bypass also modified granulocytes by activating nuclear factor- $\kappa \mathrm{B}$ (1.6-fold), whereas p38 was not altered. Histologic analyses revealed that cardiopulmonary bypass promoted acute tubular necrosis. Pretreatment of animals with sulforaphane reduced $\mathrm{p} 38(90 \%$ reduction) and nuclear factor- $\kappa \mathrm{B}(50 \%$ reduction) phosphorylation in leukocytes and protected kidneys from injury.

Conclusions: Systemic inflammatory responses after cardiopulmonary bypass were associated with activation of p38 and nuclear factor- $\kappa$ B pathways in circulating leukocytes. Inflammatory responses to cardiopulmonary bypass can be reduced by sulforaphane, which reduced leukocyte activation and protected against renal injury. (J Thorac Cardiovasc Surg 2014;148:690-7)

Supplemental material is available online.

Cardiac surgery with cardiopulmonary bypass (CPB) can lead to a spectrum of postoperative end-organ

From the BHF Cardiovascular Sciences Unit, ${ }^{\mathrm{a}}$ National Heart and Lung Institute, Imperial College London, London, United Kingdom; Department of Cardiovascular Science, ${ }^{\mathrm{b}}$ University of Sheffield, Sheffield, United Kingdom; Department of Anaesthesia, ${ }^{\mathrm{c}}$ Toronto General Hospital, Toronto, Ontario, Canada; Department of Clinical Perfusion Science, ${ }^{\mathrm{d}}$ Hammersmith Hospital, London, United Kingdom; School of Pharmacy, ${ }^{\mathrm{e}}$ Sungkyunkwan University, Seoul, Republic of Korea; and Department of Cardiothoracic Surgery, ${ }^{\mathrm{f}}$ National Heart and Lung Institute, Imperial College London, London, United Kingdom.

Funded by the British Heart Foundation, London, United Kingdom, and Heart Research UK, Leeds, United Kingdom.

Disclosures: John Mulholland reports lecture fees from Terumo. All other authors have nothing to disclose with regard to commercial support.

Received for publication Oct 11, 2013; revisions received Dec 10, 2013; accepted for publication Dec 20, 2013; available ahead of print Feb 9, 2014.

Address for reprints: Paul C. Evans, PhD, Department of Cardiovascular Science, Medical School, University of Sheffield, Beech Hill Rd, Sheffield S10 2RX, United Kingdom (E-mail: paul.evans@sheffield.ac.uk).

$0022-5223 / \$ 36.00$

Copyright (c) 2014 by The American Association for Thoracic Surgery

http://dx.doi.org/10.1016/j.jtcvs.2013.12.048 complications. $^{1-4}$ Systemic inflammation after CPB is believed to contribute to various pathophysiologic outcomes, including renal, pulmonary, and myocardial damage. ${ }^{5,6}$ The underlying mechanism is likely to be multifactorial, involving operative trauma, hemodilution and endothelial damage by edema, ischemia/reperfusion of organs, and contact-activation of blood components during CPB. ${ }^{1-8}$ Despite these insights, the mechanisms that control systemic inflammatory responses to cardiac surgery remain poorly characterized at the molecular level. To illuminate this subject, we performed CPB under highly controlled experimental conditions using a porcine model. Pigs were chosen because they have a circulation that is anatomically and physiologically similar to that of humans. In addition, the pig is becoming an increasingly attractive species for cardiovascular research, with sequencing of the porcine genome completed and an expanding reagent base. ${ }^{9,10}$ The activities of proinflammatory p38 mitogenactivated protein (MAP) kinase and RelA (a member of the nuclear factor $-\kappa \mathrm{B}[\mathrm{NF}-\kappa \mathrm{B}]$ family of transcription factors) ${ }^{11-17}$ were monitored in leukocytes and in renal, lung, and myocardial tissues of pigs exposed to CPB to assess 


\section{Abbreviations and Acronyms \\ ATN = acute tubular necrosis \\ $\mathrm{CPB}=$ cardiopulmonary bypass \\ IL = interleukin \\ IV $=$ intravenous \\ $\mathrm{NF}-\kappa \mathrm{B}=$ nuclear factor $-\kappa \mathrm{B}$ \\ MAP $=$ mitogen-activated protein \\ $\mathrm{PE} \quad=$ phycoerythrin \\ RT-PCR $=$ real-time polymerase chain reaction \\ $\mathrm{TNF} \alpha=$ tumor necrosis factor $-\alpha$}

the potential role of these molecules in systemic inflammatory responses.

Given that inflammation in response to cardiac surgery with CPB is induced by a predictable stimulus, it may be possible to prevent or reduce inflammation by pretreatment with an anti-inflammatory compound. We focused on the potential anti-inflammatory effects of sulforaphane. This compound is an isothiocyanate that acts as a potent inducer of antioxidants via the transcription factor $\mathrm{Nrf} 2{ }^{18-22}$ Sulforaphane is produced during dietary consumption of the precursor glucoraphanin, which is found in green vegetables and is particularly abundant in broccoli sprouts. ${ }^{23,24}$ Preclinical studies from our group and others have demonstrated that sulforaphane suppresses inflammation by inhibiting activation of $\mathrm{p} 38$ and NF- $\kappa \mathrm{B} \cdot{ }^{21,22,25-27} \mathrm{We}$ examined whether pretreatment using sulforaphane can reduce inflammation and tissue injury in response to $\mathrm{CPB}$.

\section{MATERIALS AND METHODS \\ Materials}

Fluorescent (phycoerythrin [PE]-Cy7-conjugated) antibodies that recognize Thr180/Tyr182 phosphorylated p38 and PE-conjugated antibodies that recognize Ser529 phosphorylated RelA (NF- $\kappa$ B) were purchased from BD Biosciences (San Jose, Calif). Buffers for intracellular staining were obtained from BD Biosciences. Primary antibodies that recognize Thr180/Tyr182 phosphorylated p38 or Ser536 phosphorylated RelA (NF- $\kappa$ B) were purchased from New England Biolabs (Ipswich, Mass). All other reagents were obtained from Sigma-Aldrich (St Louis, Mo).

\section{Animal Model}

Female Landrace pigs (50-60 kg) were used according to UK Home Office regulations and Directive 2010/63/EU of the European Parliament and in compliance with the Guide for the Care and Use of Laboratory Animals (http://www.nap.edu/catalog.php?record_id=12910). They were acclimatized for 1 week before surgery, and their health and absence of infection were verified by veterinary inspection. Animals were sedated using intramuscular ketamine $(20 \mathrm{mg} / \mathrm{kg}) / x y l a z i n e ~(2 \mathrm{mg} / \mathrm{kg})$ before the induction of anesthesia with $5 \%$ isoflurane gas and oxygen flow rates of 8 to $10 \mathrm{~L} / \mathrm{min}$. A 21 -gauge cannula was inserted in an ear vein to facilitate intravenous (IV) administration of substances. After intubation, anesthesia was maintained with an isoflurane $/ \mathrm{O}_{2}$ mixture. Immediately after the induction of anesthesia, pigs were treated with a single dose of sulforaphane $(2 \mathrm{mg} /$ $\mathrm{kg}$, IV injection) or an equivalent volume of the vehicle (saline, IV injection) as a control (5 animals per group). Continuous arterial blood pressure monitoring was instituted via an indwelling arterial line in the external carotid artery after surgical neck dissection. After median sternotomy using a gigli saw, IV heparin was administered (300 IU/kg). The aorta and right atrium were then cannulated, and normothermic $\left(38^{\circ} \mathrm{C}-39^{\circ} \mathrm{C}\right)$ nonpulsatile CPB was maintained for 2 hours using a Stöckert multiflow roller pump (Sorin Group GmbH, Munich, Germany) generating a forward flow of 2 to $4 \mathrm{~L} / \mathrm{min}$ with line pressures less than $300 \mathrm{~mm} \mathrm{Hg}$. Gas exchange was achieved via a hollow fiber-membrane oxygenator apparatus (Dideco Biomedical, Mirandola, Italy). Mean arterial pressures between 50 and 65 $\mathrm{mm} \mathrm{Hg}$ were achieved with incremental doses of metaraminol, as required. The adequacy of CPB was checked by blood gas analysis at 30-minute intervals. Lung ventilation was discontinued during this period. Arterial blood samples were taken before surgery, after sternotomy and cannulation but before $\mathrm{CPB}$, and at varying times after the commencement of $\mathrm{CPB}$. On completion of the CPB period, the experimental animal was terminated using IV phenobarbital. Immediately after termination, renal, pulmonary, and myocardial tissues were removed. Portions were snap-frozen using liquid nitrogen and stored at $-80^{\circ} \mathrm{C}$ (before analysis by Western blotting or real-time polymerase chain reaction [RT-PCR]). Portions were fixed using formalin and embedded in paraffin before the preparation of histologic sections.

\section{Intracellular Staining for Phosphorylated p38 Mitogen-Activated Protein Kinase and Nuclear Factor- $\kappa$ B}

Whole blood samples were incubated with Becton Dickinson (Franklin Lakes, NJ) lyse/fix buffer (containing phosphatase inhibitors) for 10 minutes at $37^{\circ} \mathrm{C}$. Leukocytes were then isolated by centrifugation $(300 \mathrm{~g}$ for 5 minutes) and washed once with phosphate-buffered saline. Cells were resuspended in $0.5 \mathrm{~mL}$ prechilled Becton Dickinson Perm Buffer III, vortexed, and incubated on ice for 30 minutes. After this, cells were washed twice with phosphate-buffered saline and resuspended in $0.5 \mathrm{~mL}$ Becton Dickinson Stain Buffer (fetal bovine serum) before incubation for 30 minutes (at room temperature) with PE-Cy7- or PE-conjugated antibodies that recognized Ser529 phosphorylated RelA (p65; NF- $\kappa$ B) or Thr180/Tyr182 phosphorylated $\mathrm{p} 38$ or isotype-matched controls, with subsequent washing and analysis by flow cytometry (Becton Dickinson). Fluorescence of PEconjugated p65 and PE-Cy7-conjugated p38 MAP kinase antibodies was quantified in granulocytes or mononuclear cells (identified by forward and side scatter plots) using Summit 4.3 software (Dako, Glostrup, Denmark).

\section{Comparative Real-Time Polymerase Chain Reaction}

RNA was extracted using the EZNA Total RNA Kit I (Omega Bio-Tek, Norcross, Ga) and reverse transcribed into cDNA using qScript cDNA Supermix (Quanta BioSciences Inc, Gaithersburg, Md). Transcript levels were quantified by comparative RT-PCR using gene-specific primers for porcine tumor necrosis factor- $\alpha(\mathrm{TNF} \alpha)$ (sense, $5^{\prime}$-GACAGATGGGCTGTACCTCA- $3^{\prime}$; antisense, $5^{\prime}$ GAGGTTGACCTTGGTCTGGT-3'), interleukin (IL)-8 (sense, $5^{\prime}$-GACCA GAGCCAGGAAGAGAC-3'; antisense, 5'-ACAGAGAGCTGCAGAAAG CA-3'), and IL-6 (sense, 5'-GCTTCCAATCTGGGTTCAAT-3'; antisense, $5^{\prime}$-CTAATCTGCACAGCCTCGAC- ${ }^{\prime}$ ) using PerfeCTa SYBR Green Supermix (Quanta BioSciences Inc) and the CFX96 RT-PCR Detection System (Bio-Rad Laboratories, Inc, Hercules, Calif). Reactions were performed in triplicate. Relative gene expression was calculated by comparing the number of thermal cycles that were necessary to generate threshold amounts of product. Data were pooled from 3 independent experiments, and mean values were calculated with standard deviations.

\section{Cell Culture}

Porcine aortas were obtained from a local abattoir. Porcine aortic endothelial cells were collected and cultured as described. ${ }^{28}$

\section{Western Blotting}

Levels of particular proteins were measured in cytosolic or nuclear lysates prepared using the Nuclear Extraction Kit (Active Motif, Carlsbad, 
GRANULOCYTES
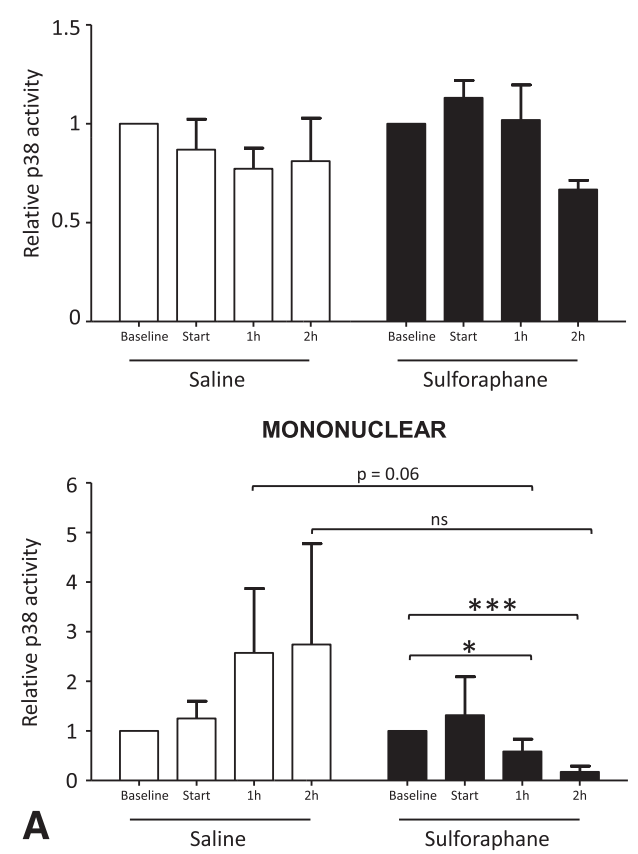

GRANULOCYTES
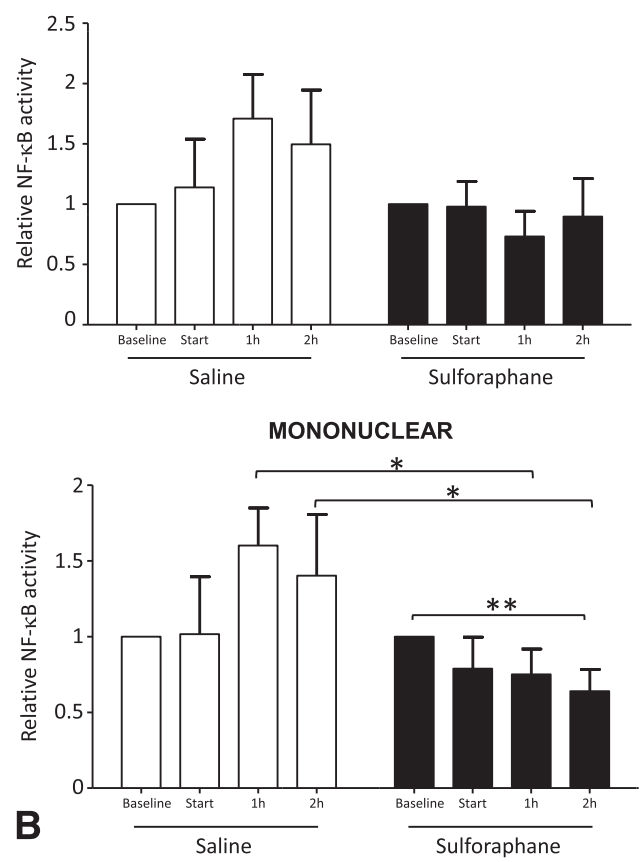

FIGURE 1. p38 and NF- $\kappa$ B activation in leukocytes in response to CPB was suppressed by pretreatment with sulforaphane. Animals were treated with sulforaphane or vehicle alone as a control and then subjected to CPB for 2 hours. Peripheral blood samples were collected before sulforaphane or vehicle injection (baseline), immediately before CPB (cannulation), and at varying times after CPB initiation. Leukocytes were fixed and permeabilized before intracellular staining using Alexafluor568-conjugated antibodies that recognize (A) Thr180/Tyr182 phosphorylated p38 or (B) Ser529 phosphorylated RelA or with isotype-matched irrelevant antibodies as a control. After lysis of red blood cells, fluorescence of granulocytes or mononuclear cells was quantified by flow cytometry (after gating of cells by size and granularity). Mean fluorescence levels were calculated after subtracting values from isotype-control antibodies. Mean values pooled from 5 animals per group are shown with standard deviations. $* P<.05$, $* * P<.01, * * * P<.001 . N F-\kappa B$, Nuclear factor- $\kappa \mathrm{B} ; n s$, not significant.

Calif) by Western blotting using specific primary antibodies, horseradish peroxidase-conjugated secondary antibodies, and chemiluminescent detection.

\section{Morphologic Studies}

Sections made from formalin-fixed, paraffin-embedded tissues were incubated in xylene for 5 minutes and hydrated by sequential exposure to decreasing concentrations of ethanol $(100 \%$ to $50 \%)$ and water. Sections were stained with hematoxylin-eosin before histologic assessment. Morphology and injury of myocardial, pulmonary, and renal tissues were assessed independently by an experienced pathologist who was blinded to the experimental design.

\section{Plasma Sulforaphane Assay}

Sulforaphane levels were measured in plasma samples by liquid chromatography mass spectrometry. High-performance liquid chromatography was performed with a 2690 Separation Module system (Waters Associates, Milford, Mass) equipped with a phenomenex Gemini $3 \mu$ C18 110A column $(150 \times 2 \mathrm{~mm})$ using a isocratic elution (acetonitrile $/ 0.1 \%$ formic acid in water $=50: 50$ ). The flow rate of the mobile phase and the column oven temperature were set at $0.2 \mathrm{~mL} / \mathrm{min}$ and $30^{\circ} \mathrm{C}$, respectively. The high-performance liquid chromatography system was coupled to an API 2000 triple-quadrupole mass spectrometer equipped with a turbo ion spray ionization source (AB MDS Sciex, Toronto, Canada). The mass spectrometry-mass spectrometry detection was achieved using a positive ion multiple reaction monitoring mode with $\mathrm{m} / \mathrm{z}$ transitions of $177.9 \rightarrow 114.0$ for sulforaphane and $256.1 \rightarrow 167.0$ for diphenhydramine.

\section{Statistics}

Differences between samples were analyzed using an unpaired Student $t$ test or analysis of variance $(* P<.05, * * P<.01$, *** $P<.001)$.

\section{RESULTS}

Inflammatory Signaling Pathways in Leukocytes Are Activated by Cardiopulmonary Bypass

The kinetics of leukocyte activation in response to CPB were determined by measuring p38 phosphorylation and NF- $\kappa \mathrm{B}$ phosphorylation in leukocytes. Blood samples were collected preoperatively (baseline), after cannulation of the aorta and right atrium before the initiation of $\mathrm{CPB}$ (CPB start), and at 1 to 2 hours after initiation of CPB. Intracellular staining and flow cytometry demonstrated that CPB induced phosphorylation of both p38 (Figure 1, $A$ ) and NF- $\kappa$ B RelA subunits (Figure $1, B$ ) in mononuclear cells after 1 to 2 hours of CPB. CPB also modified granulocytes by activating NF- $\kappa \mathrm{B}$ (Figure $1, B$ ), whereas p38 phosphorylation was not altered (Figure 1, $A$ ).

We wanted to know the effects of CPB on the expression of inflammatory cytokines in leukocytes. Quantitative PCR analysis of whole blood revealed that TNF $\alpha$ and IL-8 transcripts were enhanced after CPB for 1 hour and subsequently declined at 2 hours post-CPB (Figure 2, $A$ and $B$ ). 
Of note, IL-6 mRNA levels in leukocytes were enhanced in pigs that were prepared for $\mathrm{CPB}$ (before the commencement of CPB; Figure 2, $C$, compare baseline with CPB start), indicating that this cytokine was induced by surgical procedures per se.

\section{Inflammatory Signaling Pathways in Leukocytes Are Attenuated by Sulforaphane Pretreatment}

The influence of sulforaphane on physiologic responses to $\mathrm{CPB}$ was studied under well-controlled experimental conditions by pretreating pigs with sulforaphane (IV 2 $\mathrm{mg} / \mathrm{kg}$ ) or saline as a control. In the first instance, we monitored plasma levels of sulforaphane by liquid chromatography mass spectrometry (Figure 3). This study demonstrated that plasma sulforaphane levels were significantly elevated immediately before the commencement of $\mathrm{CPB}$ (CPB start) and persisted for at least 2 hours in animals that were pretreated with sulforaphane. The half time of sulforaphane in the pig was approximately 2 hours. Sulforaphane was not detected in saline-treated animals, indicating that endogenous levels of this compound were negligible (Figure 3). Of particular note, pretreatment of animals with sulforaphane significantly reduced p38 and NF- $\kappa$ B phosphorylation in leukocytes (Figure 1, $A$ and $B$ ). Levels of TNF $\alpha$, IL-8, and IL-6 were also significantly reduced in pigs that were pretreated with sulforaphane compared with control animals (Figure 2, A-C). Thus, it was concluded that $\mathrm{CPB}$ triggers $\mathrm{p} 38$ and NF- $\kappa \mathrm{B}$ signaling and cytokine production in leukocytes and that these processes can be blocked by pretreatment with sulforaphane.

\section{Sulforaphane Reduces Renal Injury After Cardiopulmonary Bypass}

Histologic analyses were performed to determine the effects of porcine CPB on renal, lung, and myocardial histopathology. We did not observe histologic changes in heart or lung, suggesting that the architecture of these tissues was resistant to $\mathrm{CPB}$, within the limits of histopathology (Figure E1). Of note, our model did not involve cardioplegia or crossclamp fibrillation, and therefore the heart and lungs were perfused throughout. It is plausible that the absence of edema in heart or lung relates to the absence of ischemia/reperfusion injury in this porcine model of CPB. There was acute tubular necrosis (ATN) in renal samples from $80 \%$ of control pigs (4/5) undergoing CPB, evidenced by abnormal tubular flattening and debris within the tubular lumina (open arrows in Figure 4, A, saline; key features shown at higher magnification in the insets). By contrast, ATN was not observed in kidneys from pigs pretreated with sulforaphane before CPB $(P<.05$; Figure $4, A)$. This indicates that sulforaphane pretreatment protects kidneys from damage in response to surgery with $\mathrm{CPB}$.

The potential influence of sulforaphane on p38 and $\mathrm{NF}-\kappa \mathrm{B}$ phosphorylation in renal, lung, and myocardial tissues was determined by Western blotting. To validate the technique, we identified phosphorylated forms of $\mathrm{p} 38$ or RelA NF- $\kappa \mathrm{B}$ subunits in cultured porcine aortic endothelial cells stimulated with PMA, which served as a positive control for antibody binding (Figure 4, B). Phosphorylated forms of $\mathrm{p} 38$ or NF- $\kappa \mathrm{B}$ (RelA) were not detected in renal (Figure $4, B$ ) or lung (Figure E2) tissues from pigs exposed to $\mathrm{CPB}$, whereas p38 phosphorylation was detected in the myocardium (Figure E2). Sulforaphane pretreatment did not influence p38 or NF- $\kappa \mathrm{B}$ (RelA) activation by phosphorylation in tissues (Figure $4, B$, and Figure E2), indicating that its protective effects are not due to local suppression of either of these signaling pathways. Quantitative RT-PCR demonstrated that sulforaphane reduced expression of IL-6 and TNF $\alpha$ in lung (Figure E3) but did not alter inflammatory transcripts in renal tissues (Figure 4,C). Thus, although sulforaphane can influence cytokine production in tissues, this effect does not account for its ability to reduce ATN in response to surgery with CPB.

Cardiac surgery with CPB activated p38 and NF- $\kappa$ B pathways in circulating leukocytes, and this was associated with ATN. Pretreatment of animals using a single dose of sulforaphane suppressed leukocyte activation and protected against renal injury in response to CPB.

\section{DISCUSSION}

Clinical studies of inflammatory responses to cardiac surgery are complicated by variation in patient demographics, pathophysiology of the primary disease, comorbidities, and polypharmacy. Variation also arises operatively in the duration of surgery and exposure to $\mathrm{CPB}$, which depend on the complexity of the operation. To minimize these sources of variation, we have established a large animal model of CPB in which healthy female pigs of similar age were exposed to $\mathrm{CPB}$ for a uniform duration. The study allowed assessment of the kinetics of leukocyte activation in response to CPB under well-controlled experimental conditions. It also allowed detailed examination of inflammatory gene expression in various tissue components (heart, kidney, lung) not normally procured in human subjects.

On the other hand, our study was associated with several limitations, including the relatively small sample size used and use of a single parameter to determine renal function. In addition, the heart was not excluded and not arrested during the study. Thus, although the porcine model allowed analysis of the effects of surgical preparation and CPB on inflammatory responses, the potential influence of cardiac isolation from the circulation was not assessed. Further studies are now required to confirm our observations using additional readouts of renal function and using animal models and clinical protocols that include cardioplegia or crossclamp fibrillation to achieve myocardial standstill. 

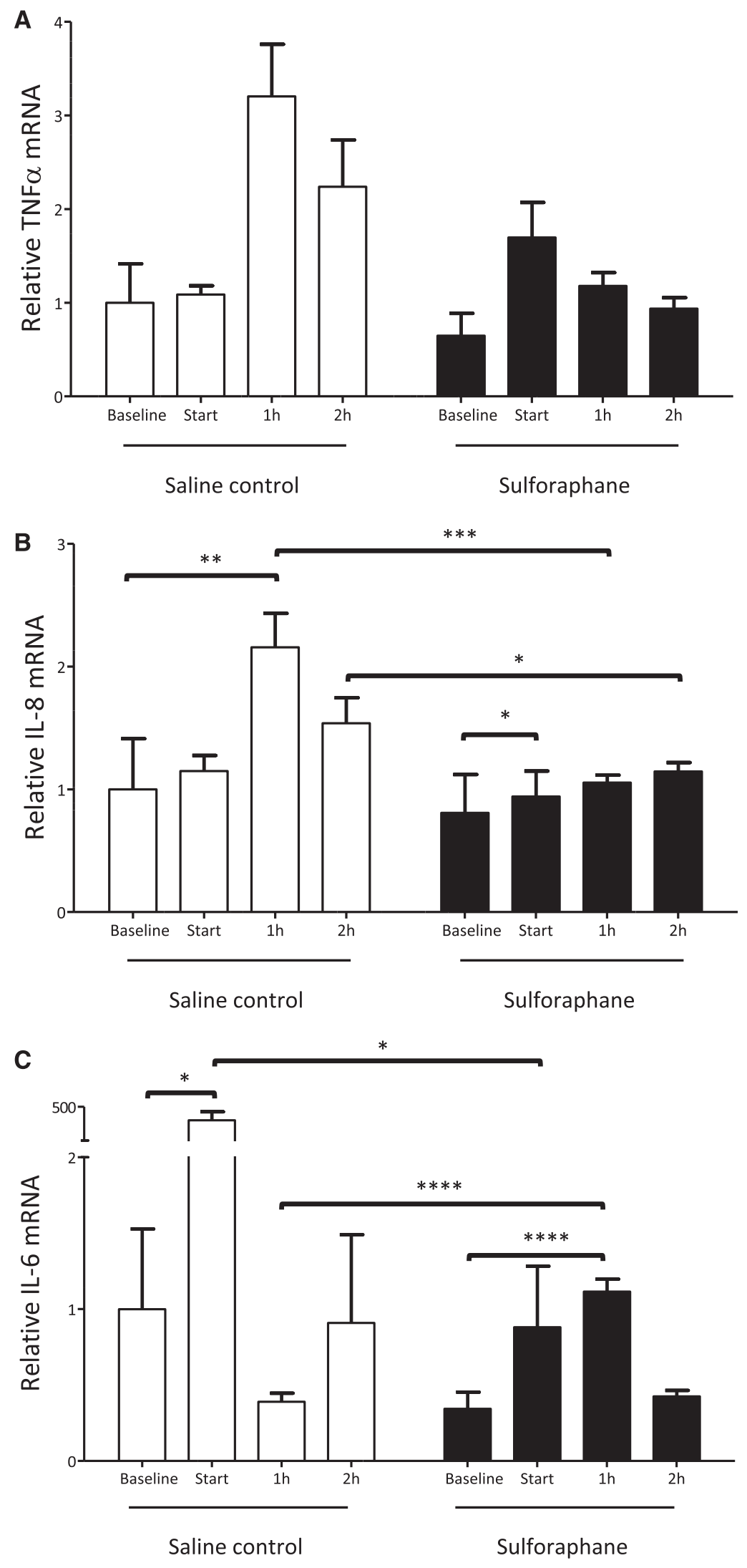


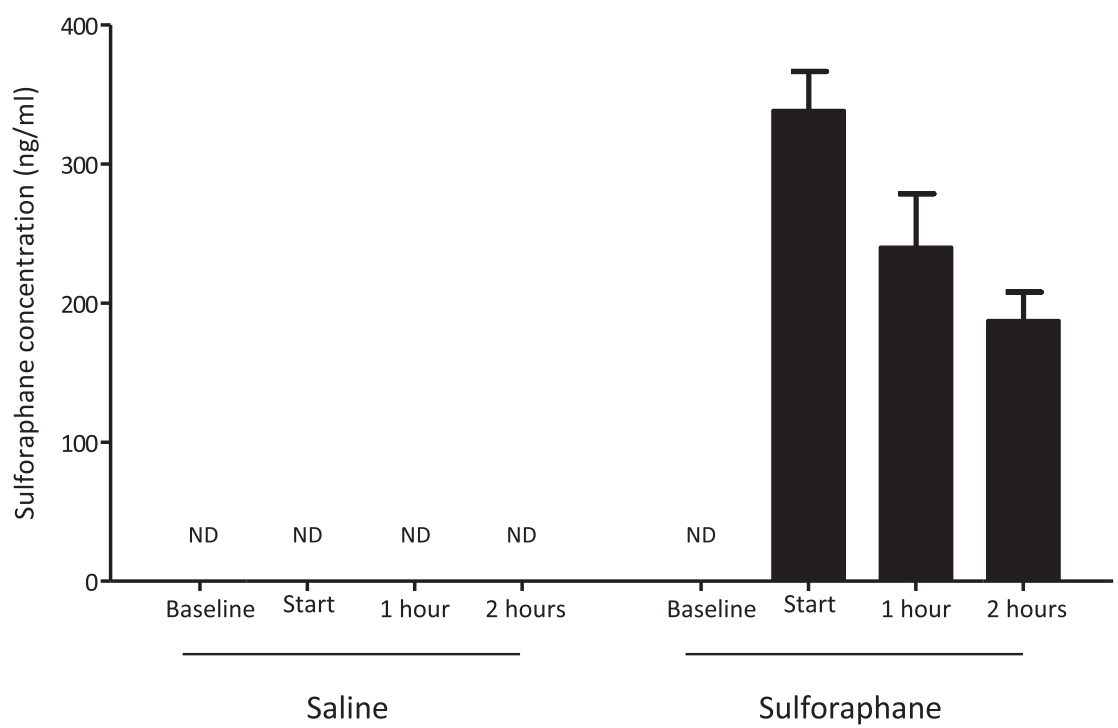

FIGURE 3. Plasma sulforaphane levels in experimental groups. Animals were treated with sulforaphane or vehicle alone as a control and then subjected to CPB for 2 hours. Plasma samples were collected before sulforaphane or vehicle injection (baseline), immediately before CPB (cannulation), and at varying times after CPB initiation. Sulforaphane levels were determined by liquid chromatography mass spectrometry (not detected). Data were pooled from 5 animals, and mean levels \pm standard deviations are shown. $N D$, Not detected.

Our study has generated fundamental information on the molecular mechanisms that regulate systemic inflammation after CPB and may allow early diagnosis of inflammatory injury. With the use of the porcine model, we demonstrate for the first time that surgery with CPB leads to p38 and $\mathrm{NF}-\kappa \mathrm{B}$ phosphorylation in leukocytes. The underlying mechanism may involve reperfusion injury and contactactivation of blood components. ${ }^{29,30}$ Of note, IL-6 induction in leukocytes was evident at the time of cannulation before $\mathrm{CPB}$, indicating that median sternotomy or cannulation of the aorta and right atrium per se was sufficient to activate inflammatory signaling in leukocytes. It is likely that sternotomy and cannulation trigger inflammatory pathways by promoting the release of damage-associated molecular patterns into the circulation ${ }^{8,31}$; however, further studies are required to identify the particular molecular triggers that are responsible. We conclude that several aspects of the surgical process contribute to systemic leukocyte activation, including sternotomy/cannulation and CPB.

Given the known role of $\mathrm{p} 38$ and NF- $\kappa \mathrm{B}$ in the transcriptional induction and stability of proinflammatory molecules, ${ }^{11-17}$ we reasoned that targeting of these molecules may dampen systemic inflammation in response to CPB. To test this hypothesis, we pretreated experimental animals with sulforaphane, an isothiocyanate from green vegetables in the Brassica genus (eg, broccoli, pak choi). Sulforaphane was selected for study because it is a potent indirect antioxidant that induces numerous endogenous antioxidant enzymes (eg, HO-1, ferritin) via the transcription factor Nrf2. ${ }^{19}$ Moreover, we previously demonstrated that sulforaphane can suppress arterial inflammation in rodents, ${ }^{21}$ and several groups demonstrated that this compound can inhibit MAP kinases and NF- $\kappa$ B in cultured vascular cells and leukocytes. ${ }^{18-22,25-27}$

We observed that sulforaphane pretreatment reduced p38 and NF- $\kappa \mathrm{B}$ activation and suppressed inflammatory cytokine expression in circulating leukocytes in pigs exposed to $\mathrm{CPB}$. Although treatment with sulforaphane reduced ATN in response to CPB, it did not influence inflammatory signaling or cytokine expression in renal tissues. These data suggest that sulforaphane protects the kidney from injury in response to $\mathrm{CPB}$ via inactivation of inflammatory signaling pathways in leukocytes. Although the mechanism underlying the differential effects of sulforaphane on leukocyte and nonimmune tissues remains uncertain, it is plausible that the bioavailability of this compound is elevated in the circulation or that leukocytes are particularly sensitive to endogenous antioxidants.

FIGURE 2. Inflammatory cytokine induction in response to CPB was reduced by pretreatment with sulforaphane. Animals were treated with sulforaphane or vehicle alone as a control and then subjected to CPB for 2 hours. Peripheral blood samples were collected before sulforaphane or vehicle injection (baseline), immediately before CPB (cannulation), and at varying times after CPB initiation. TNF $\alpha$ (A), IL-8 (B), and IL-6 (C) transcript levels were quantified by RT-PCR. Mean values pooled from 5 animals per group are shown with standard deviations. $* P<.05, * * P<.01, * * * P<.001 . I L$, Interleukin; $T N F \alpha$, tumor necrosis factor- $\alpha$; $m R N A$, messenger RNA. 

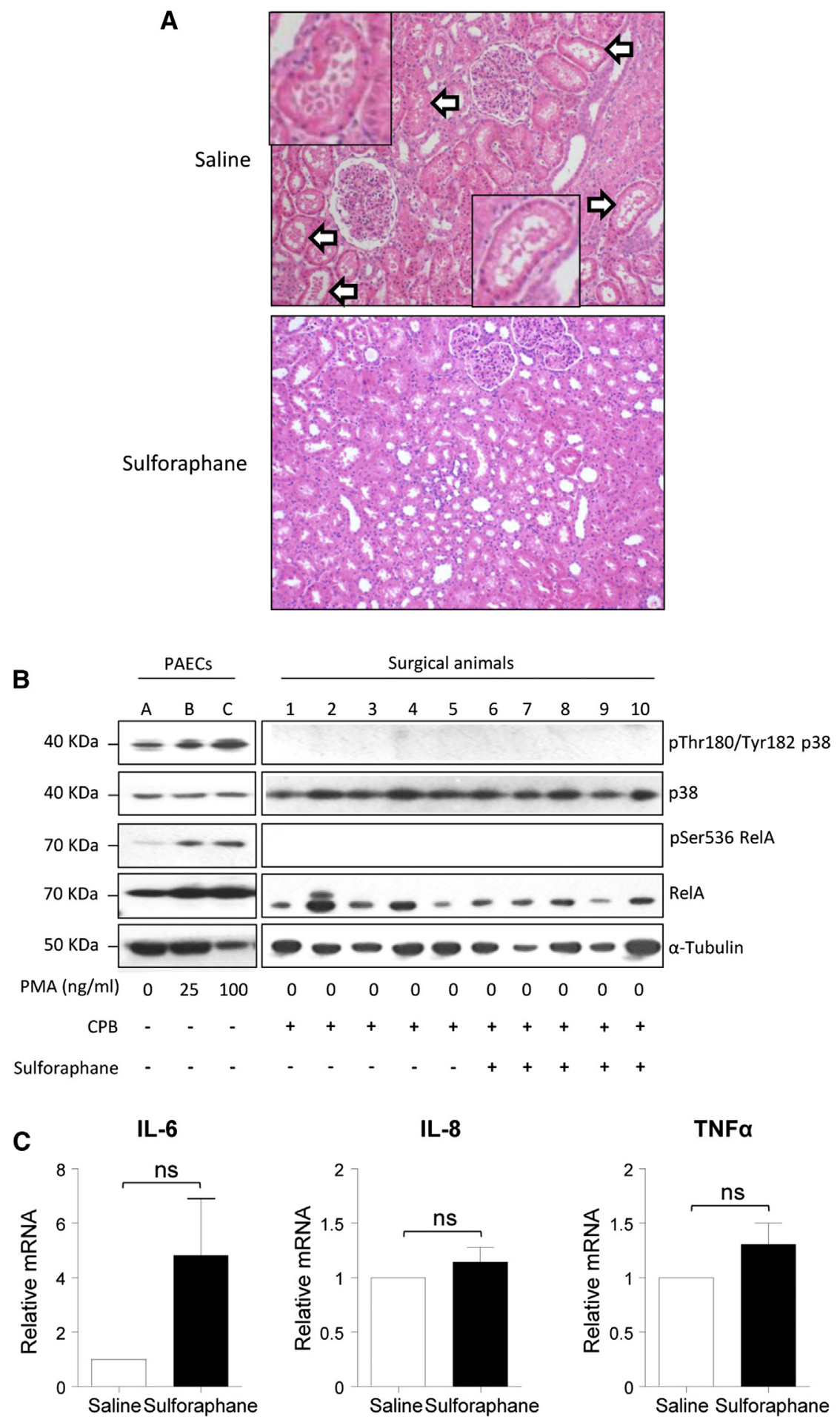

FIGURE 4. Sulforaphane pretreatment reduces acute renal injury in response to CPB. Animals were treated with sulforaphane (animals 6-10) or vehicle alone as a control (animals 1-5) and then subjected to CPB for 2 hours. Renal tissues were harvested. A, Tissue sections were stained with hematoxylin-eosin before histologic assessment by an experienced pathologist who was blinded to the experimental design. Representative images are shown. Open arrows indicate abnormal tubular flattening and debris within the tubular lumina. B, Renal tissue lysates were tested by Western blotting using antibodies that recognize Thr180/Tyr182 phosphorylated p38, total p38, Ser536 phosphorylated RelA, or total RelA, and by using anti- $\alpha$-tubulin antibodies to assess total protein levels. Lysates from phorbol myristyl acetate-stimulated porcine aortic endothelial cells (known to contain phosphorylated p38 and RelA) were tested in parallel and served as a positive control for antibody binding. C, IL-6, IL-8, and TNF $\alpha$ transcript levels were quantified by RT-PCR. Data were pooled from 5 animals, and mean values \pm standard deviations are shown. $C P B$, Cardiopulmonary bypass; $I L$, interleukin; $n s$, not significant; $P A E C$, porcine aortic endothelial cell; PMA, phorbol myristyl acetate; TNF $\alpha$, tumor necrosis factor- $\alpha$; $m R N A$, messenger RNA. 


\section{CONCLUSIONS}

Our observations have therapeutic significance for patients undergoing CPB because pharmacokinetic studies in humans revealed that consumption of broccoli leads to efficient uptake of sulforaphane from the gastrointestinal tract. $^{23,24,32}$ A single portion of broccoli cress generated sulforaphane concentrations in plasma that reached approximately $1 \mu \mathrm{mol} / \mathrm{L}$ at 1 hour after feeding and were sufficient to dampen inflammatory responses. ${ }^{23,24,32}$ Although sulforaphane is rapidly cleared from plasma, consumption of broccoli can induce antioxidant enzymes for at least 24 hours in leukocytes of healthy volunteers. ${ }^{32}$ Of particular note, a clinical trial is under way to assess the effects of broccoli intake on plasma cholesterol levels, blood pressure, and pulse-wave velocity (a measure of arterial stiffness) in subjects with elevated cardiovascular risk (ClinicalTrials.gov NCT01114399). Thus, further studies are required to examine whether consumption of sulforaphane-containing vegetables before surgery with CPB can benefit patients by reducing systemic inflammation.

The authors thank Angela Kerton, Albert Busza, Florine Morrison, Ciara Clarke, Maeve Troy, and Ray Edgar for technical assistance.

\section{References}

1. Day JR, Taylor KM. The systemic inflammatory response syndrome and cardiopulmonary bypass. Int J Surg. 2005;3:129-40.

2. Evans BJ, Haskard DO, Finch JR, Hambleton IR, Landis RC, Taylor KM. The inflammatory effect of cardiopulmonary bypass on leukocyte extravasation in vivo. J Thorac Cardiovasc Surg. 2008;135:999-1006.

3. Ascione R, Lloyd CT, Underwood MJ, Lotto AA, Pitsis AA, Angelini GD. Inflammatory response after coronary revascularization with or without cardiopulmonary bypass. Ann Thorac Surg. 2000;69:1198-204.

4. Fransen E, Maessen J, Dentener M, Senden N, Geskes G, Buurman W. Systemic inflammation present in patients undergoing CABG without extracorporeal circulation. Chest. 1998;113:1290-5.

5. Conlon PI, Stafford-Smith M, Whit WD, Newman M, King S, Wihn MP. Acute renal failure following cardiac surgery. Nephrol Dial Transplant. 1999;14:115-9.

6. Abel RM, Buckley MJ, Austen WG, Barnett GO, Beck CHD, Fischer JE. Etiology, incidence and prognosis of renal failure following cardiac operations, results of a prospective analysis of 500 consecutive patients. J Thorac Cardiovasc Surg. 1996:71:323-33.

7. Franke A, Lante W, Fackeldey V, Becker HP, Kurig E, Zoller LG, et al. Pro-inflammatory cytokines after different kinds of cardio-thoracic surgical procedures: is what we see what we know? Eur J Cardiothorac Surg. 2005;28: 569-75.

8. Dybdahl B, Wahba A, Lien E, Flo TH, Waage A, Qureshi N, et al. Inflammatory response after open heart surgery - release of heat-shock protein 70 and signaling through toll-like receptor-4. Circulation. 2002;105:685-90.

9. Lim D, Cho YM, Lee KT, Kang Y, Sung S, Nam J, et al. The Pig Genome Database (PiGenome): an integrated database for pig genome research. Mamm Genome. 2009;20:60-6.

10. Groenen MA, Archibald AL, Uenishi H, Tuggle CK, Takeuchi Y, Rothschild MF, et al. Analyses of pig genomes provide insight into porcine demography and evolution. Nature. 2012;491:393-8.

11. Dong C, Davis RJ, Flavell RA. MAP kinases in the immune response. Annu Rev Immunol. 2002;20:55-72.
12. Hayden MS, Ghosh S. Signaling to NF-kappa B. Genes Dev. 2004;18: 2195-224.

13. Mocsai A, Jakus Z, Vantus T, Berton G, Lowell CA, Ligeti E. Kinase pathways in chemoattractant-induced degranulation of neutrophils: The role of p38 mitogen-activated protein kinase activated by Src family kinases. $J$ Immunol. 2000; $164: 4321-31$

14. Cloutier A, Ear T, Blais-Charron E, Dubois CM, McDonald PP Differential involvement of NF-kappa B and MAP kinase pathways in the generation of inflammatory cytokines by human neutrophils. J Leukocyte Biol. 2007:81:567-77.

15. McDonald PP, Bald A, Cassatella MA. Activation of the NF-kappa B pathway by inflammatory stimuli in human neutrophils. Blood. 1997;89:3421-33.

16. Brach MA, Gruss HJ, Riedel D, Mertelsmann R, Herrmann F. Activation of Nf-kappa-B by interleukin-2 in human blood monocytes. Cell Growth Differ. 1992;3:421-7.

17. Clark AR, Dean JLE, Saklatvala J. Post-transcriptional regulation of gene expression by mitogen-activated protein kinase p38. Febs Lett. 2003;546:37-44.

18. Itoh K, Chiba T, Takahashi S, Ishii T, Igarashi K, Katoh Y, et al. An Nrf2 small Maf heterodimer mediates the induction of phase II detoxifying enzyme genes through antioxidant response elements. Biochem Biophys Res Comm. 1997; 236:313-22.

19. Thimmulappa RK, Mai KH, Srisuma S, Kensler TW, Yamamato M, Biswal S. Identification of Nrf2-regulated genes induced by the chemopreventive agent sulforaphane by oligonucleotide microarray. Cancer Res. 2002;62:5196-203.

20. Xue MZ, Qian QW, Adaikalakoteswari A, Rabbani N, Babaei-Jadidi R, Thornalley PJ. Activation of NF-E2-related factor-2 reverses biochemical dysfunction of endothelial cells induced by hyperglycemia linked to vascular disease. Diabetes. 2008;57:2809-17.

21. Zakkar M, Van der Heiden K, Luong LA, Chaudhury H, Cuhlmann S, Hamdulay SS, et al. Activation of nrf2 in endothelial cells protects arteries from exhibiting a proinflammatory state. Arterioscler Thromb Vasc Biol. 2009; 29:1851-7.

22. Lin W, Wu RT, Wu TY, Khor TO, Wang H, Kong AN. Sulforaphane suppressed LPS-induced inflammation in mouse peritoneal macrophages through Nrf2 dependent pathway. Biochem Pharmacol. 2008;76:967-73.

23. Ye LX, Dinkova-Kostova AT, Wade KL, Zhang YS, Shapiro TA, Talalay P Quantitative determination of dithiocarbamates in human plasma, serum, erythrocytes and urine: pharmacokinetics of broccoli sprout isothiocyanates in humans. Clin Chim Acta. 2002;316:43-53.

24. Hanlon N, Coldham N, Gielbert A, Sauer MJ, Ioannides C. Repeated intake of broccoli does not lead to higher plasma levels of sulforaphane in human volunteers. Cancer Lett. 2009;284:15-20.

25. Kim JY, Park HJ, Um SH, Sohn EH, Kim BO, Moon EY, et al. Sulforaphane suppresses vascular adhesion molecule- 1 expression in TNF- $\alpha$-stimulated mouse vascular smooth muscle cells: involvement of the MAPK, NF- $\kappa \mathrm{B}$ and AP-1 signaling pathways. Vascul Pharmacol. 2012;56:131-41.

26. Chen XL, Dodd G, Kunsch C. Sulforaphane inhibits TNF-alpha-induced activation of p38 MAP kinase and VCAM-1 and MCP-1 expression in endothelial cells. Inflamm Res. 2009;58:513-21.

27. Heiss E, Herhaus C, Klimo K, Bartsch H, Gerhäuser C. Nuclear factor kappa B is a molecular target for sulforaphane-mediated anti-inflammatory mechanisms. J Biol Chem. 2001;276:32008-15.

28. Bogle RG, Baydoun AR, Pearson JD, Mann GE. Regulation of L-arginine transport and nitric oxide release in superfused porcine aortic endothelial cells. J Physiol. 1996;490:229-41.

29. Zahler S, Massoudy P, Hartl H, Hähnel C, Meisner H, Becker BF. Acute cardiac inflammatory responses to postischemic reperfusion during cardiopulmonary bypass. Cardiovasc Res. 1999;4:722-30.

30. Liangos O, Domhan S, Schwager C, Zeier M, Huber PE, Addabbo F, et al. Whole blood transcriptomics in cardiac surgery identifies a gene regulatory network connecting ischemia reperfusion with systemic inflammation. PLoS One. 2010; 5:e13658.

31. Zhang Q, Raoof M, Chen Y, Sumi Y, Sursal T, Junger W, et al Circulating mitochondrial DAMPs cause inflammatory responses to injury. Nature. 2010;464:104-8.

32. Riedl MA, Saxon A, Diaz-Sanchez D. Oral sulforaphane increases Phase II antioxidant enzymes in the human upper airway. Clin Immunol. 2009;130: 244-51. 


\section{ONLINE METHODS SUPPLEMENT Animal Model}

Female Landrace pigs, with a mean weight of $53.6 \mathrm{~kg}$ (range, 49.6-61.2 kg), were studied according to UK Home Office regulations and after appropriate local ethical review. Animals were fasted for 12 hours before surgery. They were allowed access to water without restriction during this time. Animals were then sedated using intramuscular ketamine $(20 \mathrm{mg} / \mathrm{kg}) / x y l a z i n e ~(2 \mathrm{mg} / \mathrm{kg})$ before the induction of anesthesia with $5 \%$ isoflurane gas and oxygen flow rates of 8 to $10 \mathrm{~L} / \mathrm{min}$. Animals were intubated, and anesthesia was maintained with an isoflurane $/ \mathrm{O}_{2}$ mixture driven by medical air. Pigs were treated with sulforaphane $(2 \mathrm{mg} / \mathrm{kg} \mathrm{IV})$ or saline as a control.

Animals were then positioned supine with attachment of diathermy, rectal temperature probe, and electrocardiogram electrodes with continuous monitoring. All areas outside of the anesthetic and surgical field were blanketed to maintain temperature homeostasis with the assistance of a heated operating table. Surgery was performed using a strict aseptic technique. The operative field was cleaned with hibiscrub wash, and waterproof drapes were applied, exposing the neck and sternum. Continuous arterial blood pressure monitoring was instituted via an indwelling arterial line in the external carotid artery after surgical neck dissection. A skin incision from the supra-sternal notch to the xiphisternum was created using a 10-blade scalpel. Dissection down to the sternum was performed using hand-held diathermy at 50J with release of the supra-sternal ligament, with close attention to hemostasis throughout. Retro-sternal adhesions were released with a finger sweep before division of the sternum using a pair of heavy Mayo scissors. IV heparin was given after the completion of sternotomy (300 IU/kg). The aorta and right atrium were then dissected and exposed using hand-held diathermy at 50J. The aortic cannulation site was prepared using 2-O Ethibond double purse-string sutures ( $1 \times 1 \mathrm{~cm}$; Ethicon, St-Stevens-Woluwe, Belgium) 142 with 2 snuggers on opposing sides secured with Dunhill clips. Aortic cannulation was performed when the activated clotting time was greater than 400 seconds. The aortic pipe was inserted into the aorta, with the direction of flow orientated toward the arch and descending aorta. The right atrium was cannulated using a 2-stage venous cannula, directing the distal end toward the inferior vena cava. The CPB circuit was primed with Hartmann's solution (2000 mL) and heparin (5000 IU). Lines were divided and clamped in preparation for extracorporeal circulation. CPB was subsequently maintained for 2 hours while lung ventilation was discontinued. Normothermic $\left(38^{\circ} \mathrm{C}-39^{\circ} \mathrm{C}\right)$ nonpulsatile CPB was maintained using a Stöckert multiflow roller pump (Sorin Group GmbH, Munich, Germany) generating a forward flow of 2 to $4 \mathrm{~L} / \mathrm{min}$ with line pressures less than $300 \mathrm{~mm} \mathrm{Hg}$. Gas exchange was achieved via a hollow fiber-membrane oxygenator apparatus (Dideco). Mean arterial pressures between 50 and $65 \mathrm{~mm} \mathrm{Hg}$ were achieved with incremental doses of metaraminol (South Devon Healthcare, Torbay, UK), as required. The adequacy of $\mathrm{CPB}$ was checked by blood gas analysis at 30-minute intervals. The experiment was terminated using phenobarbital delivered through the CPB machine or central access site. Tissues (heart, lung, kidney, skin) were then harvested immediately.

\section{Standards and Sample Preparation for Liquid Chromatography Mass Spectrometry Analysis}

Primary stock solutions of sulforaphane and diphenhydramine (internal standard) were prepared by dissolving $5 \mathrm{mg}$ in dimethyl sulfoxide $500 \mu \mathrm{L}$ and $10 \mathrm{mg}$ in methanol $100 \mathrm{~mL}$, respectively. The standard working solutions of sulforaphane were prepared by serial dilution with acetonitrile to give working solutions with concentrations of $25,50,100,250,500$, and $1000 \mathrm{ng} / \mathrm{mL}$. The internal standard working solution $(50 \mu \mathrm{L}$, diphenhydramine $500 \mu \mathrm{g} / \mathrm{mL}$ in methanol) and acetonitrile $(200 \mu \mathrm{L})$ were added to pig plasma $(50 \mu \mathrm{L})$. The mixture was centrifuged for 10 minutes at $4000 \mathrm{rpm}$, and the supernatant was transferred to a clean tube. The supernatant was diluted 2-fold, and a portion $(10 \mathrm{~mL})$ of the solution was injected into liquid chromatography mass spectrometry. 


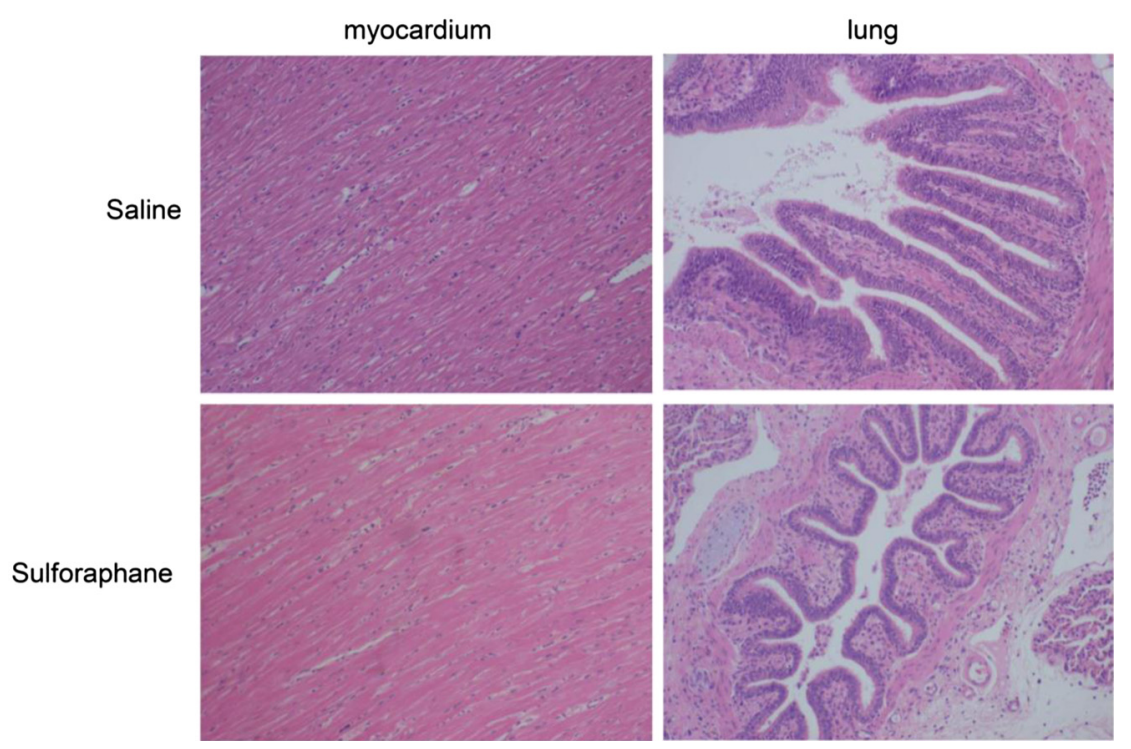

FIGURE E1. Animals were treated with sulforaphane or vehicle alone as a control and then subjected to CPB for 2 hours. Myocardial and lung tissues were harvested. Tissue sections were stained with hematoxylin-eosin before histologic assessment by an experienced pathologist who was blinded to the experimental design. Representative images are shown.

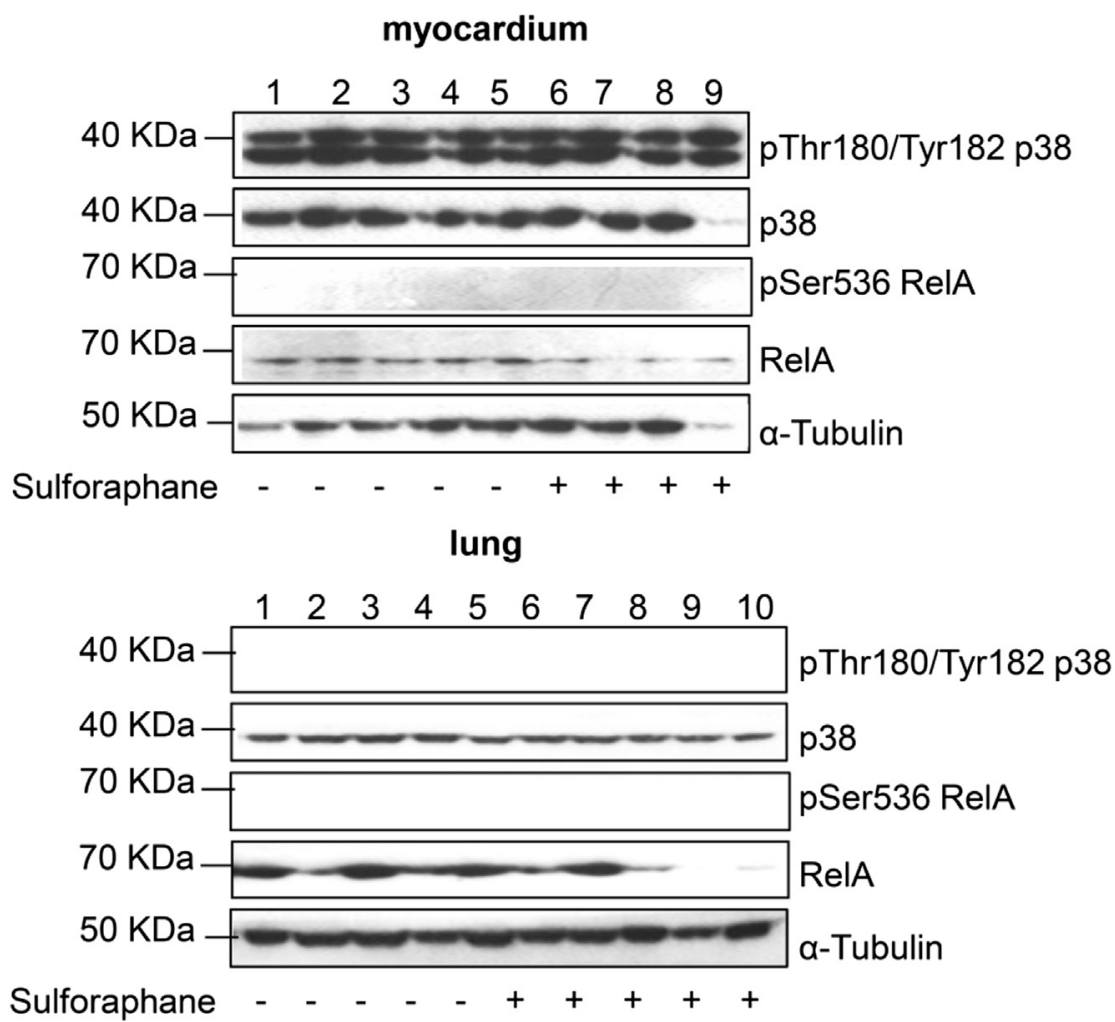

FIGURE E2. Animals were treated with sulforaphane (animals 6-10) or vehicle alone as a control (animals 1-5) and then subjected to CPB for 2 hours. Myocardial and lung tissues were harvested. Tissue lysates were tested by Western blotting using antibodies that recognize Thr180/Tyr182 phosphorylated p38, total p38, Ser536 phosphorylated RelA, or total RelA, and by using anti- $\alpha$-tubulin antibodies to assess total protein levels. 
IL-6

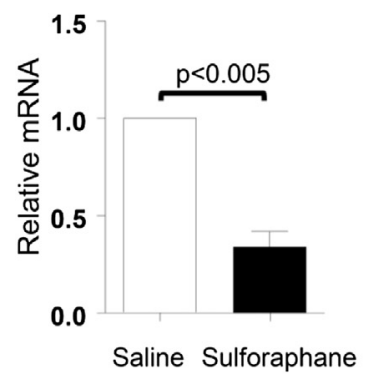

IL-8

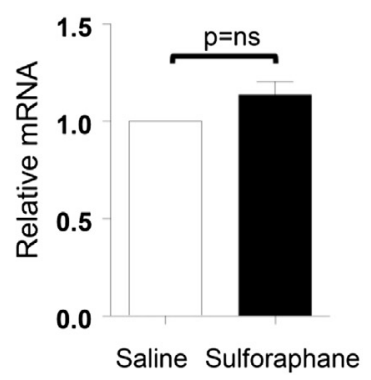

TNFa

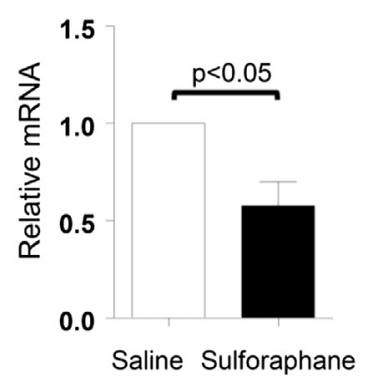

FIGURE E3. Animals were treated with sulforaphane or vehicle alone as a control and then subjected to CPB for 2 hours. Myocardial and lung tissues were harvested. IL-6, IL-8, and TNF $\alpha$ transcript levels were quantified by RT-PCR. Data were pooled from multiple animals, and mean values \pm standard deviations are shown. $I L$, Interleukin; $T N F \alpha$, tumor necrosis factor- $\alpha$; $m R N A$, messenger RNA; $n s$, not significant. 